\title{
Evaluation of Disposable and Traditional Accessory Devices for Use With a Pressurized Metered-Dose Inhaler
}

\author{
Haitham Saeed, Mohamed EA Abdelrahim, Hoda Rabea, and Heba F Salem
}

\begin{abstract}
BACKGROUND: The use of accessory devices with pressurized metered-dose inhalers (pMDIs) enhances aerosol delivery and helps overcome any lack of patient coordination when using the pMDI. The use of accessory devices could be influenced by the efficacy, availability, and cost of these devices. The aim of this study was to compare drug delivery with the pMDI alone and with non-antistatic and antistatic accessory devices. METHODS: The total emitted dose and aerodynamic characterization of salbutamol particles were measured for the pMDI alone and for the pMDI combined with 4 different accessory devices: a homemade spacer, the Dolphin spacer, the DispozABLE paper spacer, and the AeroChamber Plus valved holding chamber. Aerodynamic characterization was analyzed with an Andersen cascade impactor at an inhalation flow of 28.3 L/min, and drug deposition was measured with high-performance liquid chromatography. RESULTS: The mean \pm SD total emitted dose from the pMDI alone, $155.2 \pm 20.5 \mu \mathrm{g}$, was the greatest of all modalities, and the difference was significant $(P<.001)$. The homemade and Dolphin spacers had the highest mean \pm SD deposited amounts of salbutamol remaining on their walls (ie, 124.1 $\pm 11.1 \mu \mathrm{g}$ and $131.5 \pm 11.8 \mu \mathrm{g}$, respectively). The mean \pm SD total emitted doses with the AeroChamber Plus valved holding chamber $(61.9 \pm 8.9 \mu \mathrm{g})$ and the DispozABLE paper spacer $(76.4 \pm 8.6 \mu \mathrm{g})$ were significantly higher than the emitted doses with the other devices. The mean \pm SD fine-particle doses emitted with the AeroChamber plus valved holding chamber $(51.4 \pm 4.7 \mu \mathrm{g})$ and the DispozABLE paper spacer $(39.7 \pm 5.6 \mu \mathrm{g})$ were significantly higher than those with the other devices. The AeroChamber Plus valved holding chamber had the lowest mass median aerodynamic diameter (MMAD) values, but there were no statistically significant differences in MMAD between any of the combinations of pMDI and accessory device. CONCLUSIONS: The valved holding chamber and the paper spacer had better aerodynamic characteristics than the other devices tested. We consider the antistatic devices to be the optimum devices for aerosol delivery due to their high efficacy compared to non-antistatic devices. Key words: spacer; pMDI; salbutamol; asthma; total emitted dose. [Respir Care 2020;65(3):320-325. (C) 2020 Daedalus Enterprises]
\end{abstract}

\section{Introduction}

Inhaled medications are the most commonly used therapies for the management of asthma and chronic obstructive lung diseases because they are safer than systemically delivered therapies. ${ }^{1}$ Pressurized metered-dose inhalers (pMDIs) are widely used to deliver aerosols to patients

Drs Saeed, Abdelrahim, and Rabea are affiliated with the Clinical Pharmacy Department, Faculty of Pharmacy, Beni-suef University, Beni-suef, Egypt. Dr Salem is affiliated with the Pharmaceutics and Industrial Pharmacy Department, Beni-suef University, Beni-suef, Egypt.

The authors disclose a relationship with Clement Clarke International with obstructive lung diseases; however, only small amounts of drug reach the patient's lungs. ${ }^{2,3}$ Patients need to be taught to synchronize their breathing with the actuation of the pMDI to enhance drug deposition in the lung.4,5 Inspiratory flows of $>30 \mathrm{~L} / \mathrm{min}$ and an insufficient breathhold after inspiration also contribute to low drug delivery via pMDIs. ${ }^{4}$

Correspondence: Mohamed EA Abdelrahim PhD, Department of Clinical Pharmacy, Ahmed Hegazi Tawil street, Beni-suef University, Beni-suef 62511, Egypt. E-mail: mohamedemam9@yahoo.com.

DOI: $10.4187 /$ respcare. 06835 


\section{Disposable vs Traditional Spacers For PMDI}

It is difficult to teach patients to use a pMDI properly in an emergency situation where they need the drug to be administered very rapidly. Teaching children and elderly patients is similarly challenging. ${ }^{5,6}$ In these cases, placing an accessory device (ie, a reservoir) between the pMDI and the patient allows more time for drug inhalation. ${ }^{2,7}$ Accessory devices enhance aerosol delivery to the patient because large particles emitted by the pMDI settle inside the accessory device rather than being deposited in the mouth and throat. This increases the dose of fine particles. ${ }^{7,8}$

The construction of the accessory device affects the emitted dose of inhaled medications and influences its cost, which is important when considering the pharmacoeconomic aspects of these devices. In addition, the material from which an accessory device is made is an important factor affecting aerosol delivery. ${ }^{9}$ Most traditional accessory devices on the market are made from lightweight plastic for greater durability and enhanced device portability. ${ }^{10,11}$ Polypropylene and polycarbonate are the most commonly used materials for making plastic spacers or valved holding chambers; however, their non-conducting nature encourages electrostatic charges within the device. ${ }^{12-14}$ Because drugs released from pMDIs also are electrically charged, electrostatic reactions inevitably occur between the charged walls of the accessory device and the emitted drug. Mutual repulsion between the charged entities pushes the drug particles toward the wall of the accessory device, ${ }^{11-14}$ thus decreasing the emitted dose. ${ }^{15-17}$ According to the Global Initiative for Asthma guidelines, ${ }^{18}$ there are 2 efficient methods for neutralizing charges on the walls of accessory devices. The first involves washing the plastic accessory device in soapy water and letting it dry in the air; the residual soap acts as a surfactant. The second method involves priming the device with puffs of the drug before inspiration. These methods are effective, but they result in wasted drug or delays, and neither is suitable in emergency cases. ${ }^{18}$ Some disposable accessory devices are made of paper, which is antistatic and inexpensive. ${ }^{3}$ The aim of this study was to evaluate the efficacy of a range of accessory devices in delivering aerosolized drugs from a pMDI.

\section{Methods}

\section{Total Emitted Dose}

A pMDI containing Ventolin (GlaxoSmithKline, Cairo, Egypt) delivering a nominal dose of $100 \mu \mathrm{g}$ salbutamol per puff) was used in this study. Determinations were made for the pMDI alone and for the pMDI when attached to different accessory devices. The accessory devices were the DispozABLE paper spacer (Clement Clarke International, Harlow, United Kingdom), the Dolphin Chamber

\section{QUICK LOOK}

\section{Current knowledge}

Using an accessory device as a drug reservoir enhances aerosol delivery to patients with respiratory disease by increasing the fine-particle dose delivered to the patient and decreasing deposition of drug in the mouth and throat. The type, size, and construction of an accessory device can affect the emitted dose of inhaled medications.

\section{What this paper contributes to our knowledge}

The antistatic devices delivered a significantly greater fine-particle dose and total emitted dose; the non-antistatic devices tested were less effective than the antistatic devices tested. The antistatic accessory devices were the optimum choice for aerosol delivery due to emission of high fine particle doses.

(TMS Medikal Plastik Sanayi ve Dış Ticaret, Istanbul, Turkey), the AeroChamber Plus valved holding chamber (Trudell Medical International Europe, Hampshire, United Kingdom), and a spacer made from an empty $500-\mathrm{mL}$ plastic bottle (Fig. 1). The Dolphin Chamber and the handmade spacer were characterized as non-antistatic, whereas the AeroChamber Plus valved chamber and the DispozABLE spacer were characterized as antistatic accessory devices.

To measure the total emitted dose, we used a pMDI sampling apparatus (Copley Scientific, Nottingham, United Kingdom), a critical flow controller (Copley Scientific), and a 25-mm A/E fiberglass filter (Pall Corporation, New York) in which to collect the drug. A vacuum pump (Brook Crompton, Huddersfield, United Kingdom) was attached to the apparatus to simulate the inhalation air flow. The flow was $28.3 \mathrm{~L} / \mathrm{min}$ over duration of $8.5 \mathrm{~s}$, providing an inhalation volume equal to $4 \mathrm{~L}$. Before dosing, the mouthpiece of the pMDI/accessory device combination was inserted tightly into the sampling unit mouthpiece adapter, and the pMDI was shaken and primed by releasing 2 doses of the drug. ${ }^{19}$ During evaluations, the dose released from the pMDI or the pMDI/accessory device combination was measured by collecting 2 puffs (ie, $200 \mu \mathrm{g}$ salbutamol) emitted at $28.3 \mathrm{~L} / \mathrm{min}$. This was repeated 10 times for each pMDI/accessory device combination. When the pMDI was evaluated alone, the release of the puffs was coordinated with switching on the pump; when the accessory devices were tested, the dose was released into the accessory device chamber and the pump was switched on within $1 \mathrm{~s}$.

The salbutamol dose was trapped on filters inside the sampling apparatus. The emitted dose was recovered by 


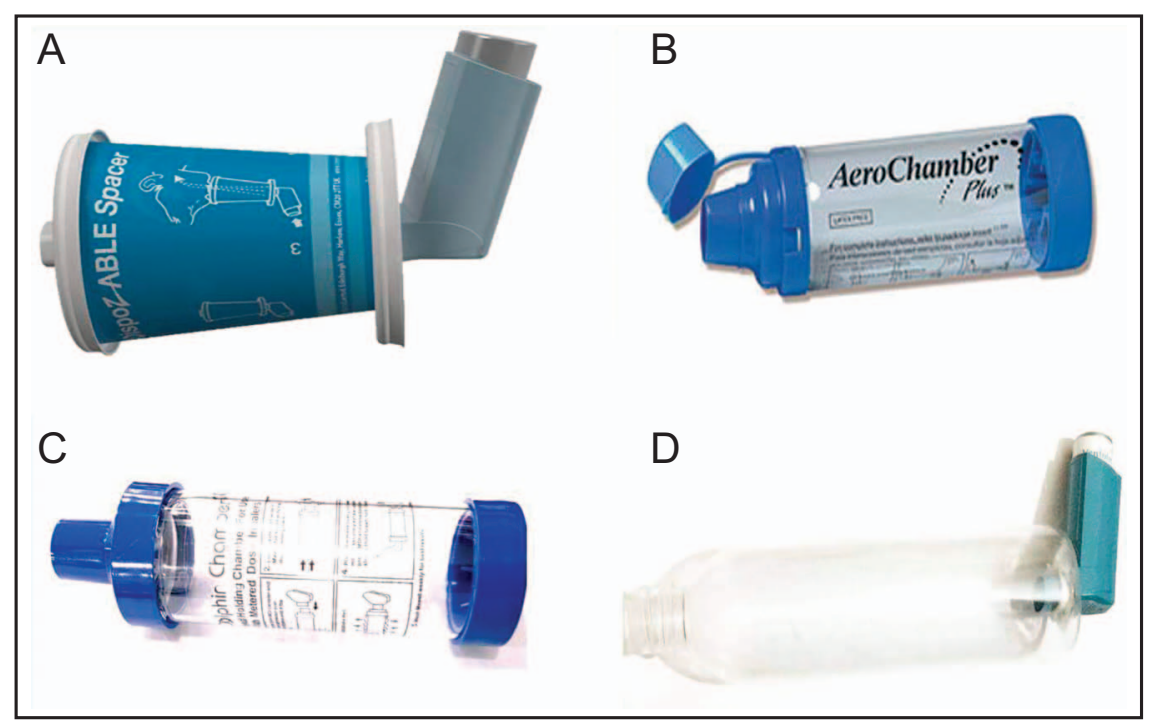

Fig. 1. Accessory devices used in this study. A: DispozABLE paper spacer; B: AeroChamber Plus valved holding chamber; C: Dolphin Chamber spacer; and D: homemade spacer.

sonicating and then rinsing the filter with $90 \%$ acetonitrile. ${ }^{20,21}$ Salbutamol was quantified with high-performance liquid chromatography with ultraviolet detection. Samples of the acetonitrile washings $(100 \mu \mathrm{L})$ were eluted on a $25 \mathrm{~mm}$ by $4.6 \mathrm{~mm}$ ZORBAX Eclipse Plus C18, ODS1 column (Agilent, Santa Clara, California) using a 90:10 $(\mathrm{v} / \mathrm{v})$ acetonitrile and water mobile phase that also contained $0.1 \%$ phosphoric acid pumped at a flow of $1 \mathrm{~mL} / \mathrm{min}(1260$ Infinity preparative pump, G1361A, Agilent). The detector (1260 Infinity Diode array detector VL, G131SD, Agilent) was set at $225 \mathrm{~nm}$ and was calibrated with solutions ranging from 4 to $100 \mu \mathrm{g} / \mathrm{mL}$ (weight/volume). The limit of detection was $0.3 \mu \mathrm{g} / \mathrm{mL}$, and the lower limit of quantification was $2.5 \mu \mathrm{g} . / \mathrm{mL} .{ }^{20,21}$

\section{Characterization of Aerodynamic Particle Size}

An Andersen MKII cascade impactor was used to determine the aerodynamic particle size of salbutamol after release from the pMDI for each of the 10 determinations with the pMDI and the pMDI/accessory device combinations. ${ }^{20,21}$ CITDAS software (Copley Scientific, Nottingham, UK) was used to determine the fine-particle dose (FPD), fine-particle fraction (FPF), and the mass median aerodynamic diameter (MMAD).

\section{Statistical Analysis}

The total emitted dose and aerodynamic particle size characterization for the different combinations and pMDI alone were compared in 2-way analysis of variance tests using SPSS 23 (SPSS, Chicago, Illinois).

\section{Results}

The emitted doses, quantities remaining in accessory devices, and aerodynamic particle size measurements are shown in Table 1.

\section{Outcomes With Metered Doses}

The mean total emitted dose from the pMDI alone (155.2/200.0 $\mu \mathrm{g} ; 77.6 \%)$ was significantly higher than any pMDI and accessory device combination $(P<.001)$. The pMDI plus Dolphin Chamber and the pMDI with a homemade spacer had the lowest emitted dose fractions ( $49.3 \mu \mathrm{g}$ or $24.7 \%$, and $52.9 \mu \mathrm{g}$ or $26.5 \%$, respectively), with large amounts of salbutamol remaining in these spacers $(P<.05)$ compared to the pMDI alone or the other pMDI/accessory device combinations (Table 1). With the pMDI alone, a mean of $49.9 \%$ of the salbutamol dose was deposited in the induction port of the cascade impactor, which is the equivalent of the patient's throat. The proportion of the dose deposited in the induction port of the cascade impactor with the $\mathrm{pMDI} / \mathrm{accessory}$ device combinations were significantly lower than with the pMDI alone $(P<.001)$. The DispozABLE paper spacer and the AeroChamber Plus valved holding chamber had lower proportions of dose deposited in the induction port $(P<.05)$ compared to the pMDI plus Dolphin Chamber and the pMDI with a homemade spacer (Table 1).

\section{Particle Size Distribution}

The AeroChamber Plus valved holding chamber had the lowest MMAD values, but there were no statistically 
Disposable vs Traditional Spacers for PMDI

Table 1. Outcome and Aerodynamic Characteristics of Salbutamol Dose Delivered via Pressurized Metered-Dose Inhaler

\begin{tabular}{lccccc}
\hline \hline & pMDI Alone & DispozABLE Spacer & Homemade Spacer & Dolphin Spacer & AeroChamber Plus* \\
\hline Emitted dose, $\mu \mathrm{g}$ & $155.2 \pm 20.5$ & $76.4 \pm 8.6$ & $52.9 \pm 9.9$ & $49.3 \pm 9$ & $61.9 \pm 8.9$ \\
Dose deposited in spacer, $\mu \mathrm{g}$ & $\mathrm{NA}$ & $111 \pm 6.2$ & $124.1 \pm 11.1$ & $131.5 \pm 11.8$ & $110.2 \pm 17.7$ \\
Dose deposited in induction port, $\mu \mathrm{g} \dagger$ & $99.7 \pm 6$ & $6.4 \pm 2$ & $7.4 \pm 2.3$ & $11.2 \pm 2.5$ & $6.8 \pm 1.6$ \\
Fine particle dose $<5 \mu \mathrm{g}$ & $24.4 \pm 5.1$ & $39.7 \pm 5.6$ & $24.8 \pm 3.7$ & $22.6 \pm 4.5$ & $51.4 \pm 4.7$ \\
Fine particle dose $<3 \mu \mathrm{g}$ & $10 \pm 2.4$ & $12.8 \pm 2.2$ & $7.5 \pm 1.6$ & $7.5 \pm 1.2$ & $18.7 \pm 2$ \\
MMAD, $\mu \mathrm{m}$ & $4.4 \pm 0.3$ & $4.6 \pm 0.2$ & $4.6 \pm 0.3$ & $4.8 \pm 0.3$ & $3.78 \pm 0.1$
\end{tabular}

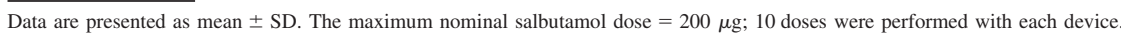

* The AeroChamber Plus is a valved holding chamber.

$\dagger$ The dose deposited in the induction port of the cascade impactor is equivalent to the dose deposited in the mouth and throat of a patient.

pMDI $=$ pressurized metered-dose inhaler

$\mathrm{NA}=$ not applicable

MMAD $=$ mass median aerodynamic diameter

significant differences in MMAD between any of the pMDI/accessory device combinations. There were no statistically significant differences in the FPD values or in the proportions of particles $<3 \mu \mathrm{g}$ or $<5 \mu \mathrm{g}$ between the DispozABLE paper spacer and the AeroChamber Plus valved holding chamber; however, values for these devices were statistically significantly higher than those for the pMDI alone and for the Dolphin Chamber and the homemade spacer $(P<.001)$. There were no statistically significant differences in FPD values or in the proportions of particles $<3 \mu \mathrm{g}$ or $<5 \mu \mathrm{g}$ between the Dolphin Chamber and the homemade spacer compared to the pMDI device alone.

\section{Discussion}

The total amount of salbutamol delivered by the pMDI and its FPD were significantly affected by the type of the accessory device used $(P<.001)$. The greater delivered dose from the pMDI alone is expected due to the absence of the accessory device, which decreases the number of large particles reaching the dose sampling unit. ${ }^{2}$ The quantities of salbutamol deposited on the walls of the AeroChamber Plus valved holding chamber were significantly lower than with other pMDI/accessory device combinations due to its antistatic lining $(P<.05)$. Conversely, amounts deposited in the non-antistatic homemade spacer and the Dolphin Chamber were the highest, reflecting the significant effect of static charge in drug deposition. ${ }^{22}$ Quantities of salbutamol deposited on the walls of the DispozABLE paper spacer were lower than those deposited on the walls of homemade and Dolphin spacers due to the absence of static charges $(P<.05)$.

The total dose delivered by the pMDI was affected by the quantity of salbutamol deposited on the walls of the accessory devices. The highest doses were delivered with the DispozABLE paper spacer, followed by AeroChamber Plus valved holding chamber. The doses delivered from the non-antistatic spacers (ie, the homemade spacer and the Dolphin Chamber) were significantly lower than those from the antistatic accessory devices $(P<.05)$. This supports the recommendation to use antistatic accessory devices for better delivery. ${ }^{23}$ Several previous studies have reported similar results, namely that the accessory device significantly increased the relative lung bioavailability compared to the pMDI alone $(P<.01) .{ }^{10,22,24,25}$ This may be because inhalation from an accessory device decreases the velocity of the aerosol particles and allows some evaporation of the propellant, thereby decreasing the particle size and the quantity of salbutamol deposited in the patient's mouth and throat (represented by the induction port of the Andersen MKII cascade impactor in this study). ${ }^{22}$ When using the pMDI without an accessory device, the majority of the emitted dose was deposited in the induction port, but when using the accessory devices, the majority of the emitted dose was deposited in the accessory device. Thus, the use of an accessory device decreases the amount deposited in the mouth and subsequently ingested by the patient, potentially leading to a reduction in side effects. ${ }^{26}$

The use of an accessory device with a pMDI is necessary to ensure the delivery of an adequate dose of drug to the lungs with minimal mouth and throat deposition; however, several factors affect the choice of accessory device, including efficacy, availability, and cost. In this study, aerodynamic characterization of the particles emitted from each accessory device was used to determine its efficacy. The results indicate that the antistatic accessory devices (ie, the AeroChamber Plus valved holding chamber and the DispozABLE paper spacer) were more effective than the non-antistatic accessory devices (ie, the Dolphin Chamber and the homemade spacer) based on lower MMAD and significantly higher FPD values $(P<.05)$. An important use for accessory devices could be to deliver inhaled medications efficiently in an emergency situation, such as an exacerbation of pulmonary obstructive disease. Because an emergency could occur anywhere and at any time, pre- 


\section{Disposable vs Traditional Spacers For PMDI}

installation of accessory devices for this condition could be difficult. Disposable spacers could address this problem if their use were shown to be feasible. However, the homemade spacer did not significantly increase the FPD compared to the use pMDI alone; it primarily made the coordination between actuation and inhalation easier, which could be the only reason for using such an accessory device. The durability of the paper and plastic spacers were tested by using them repeatedly to measure the emitted dose. Our result indicate that the paper spacer can be used on multiple occasions; however, unlike the other accessory devices, it cannot be washed, which limits its duration of use. ${ }^{27}$

\section{Limitations of the Study}

The in vitro model used in this study was effective for comparing the pMDI and the 4 accessory devices tested, but it clearly could not replicate the clinical response to salbutamol doses. Additional studies incorporating an in vivo element would provide additional guidance to clinicians in evaluating patients' ability to optimize aerosol delivery. Another limitation of the study was that we did not study all spacers and valved holding chambers that are commercially available; different shapes and materials from which the accessory devices are made may lead to different outcomes.

\section{Conclusions}

This study suggests that, based on their antistatic nature and their ability to deliver a high FPD and total emitted dose, the DispozABLE paper spacer and the AeroChamber Plus valved holding chamber are the better choices for aerosol delivery among the tested devices. The non-antistatic accessory devices were less effective than the other devices tested here, but they could help with the challenge of coordination.

\section{REFERENCES}

1. Willemse B, Toelle B, Li J, Shah S, Peat J. Use of a paper disposable cup as a spacer is effective for the first-aid management of asthma. Respir Med 2003;97(1):86-89.

2. Leung SSY, Chiow ACM, Kwok PCL, Ukkonen A, Chan HK. Effect of spacers on the bipolar electrostatic charge properties of metered dose inhaler aerosols: a case study with Tilade. J Pharm Sci 2017; 106(6):1553-1559.

3. Sanders M, Bruin R. A rationale for going back to the future: use of disposable spacers for pressurised metered dose inhalers. Pulm Med 2015;2015:176194

4. McFadden Jr E. Improper patient techniques with metered dose inhalers: clinical consequences and solutions to misuse. J Allergy Clin Immunol 1995;96(2):278-283.

5. Nicola M, Elberry A, Sayed O, Hussein R, Saeed H, Abdelrahim M. The impact of adding a training device to familiar counselling on inhalation technique and pulmonary function of asthmatics. Adv Ther 2018;35(7):1049-1058

6. Elgendy MO, Abdelrahim ME, Eldin RS. Potential benefit of repeated MDI inhalation technique counselling for patients with asthma. Eur J Hosp Pharm 2015;22(6):318-322.

7. Rau JL. Practical problems with aerosol therapy in COPD. Respir Care 2006;51(2):158-172.

8. Rahmatalla MF, Zuberbuhler PC, Lange CF, Finlay WH. In vitro effect of a holding chamber on the mouth-throat deposition of QVAR ${ }^{\circledR}$ (hydrofluoroalkane-beclomethasone dipropionate). J Aerosol Med 2002;15(4):379-385.

9. Sheth P, Bertsch MD, Knapp CL, Myrdal PB. In vitro evaluation of nonconventional accessory devices for pressurized metered-dose inhalers. Ann Allergy Asthma Immunol 2014;113(1):55-62.

10. Goncalves TM, Alhanout K, Nicolay A, Dubus J-C, de Santana DP, Andrieu V. Comparative in vitro performance of three small-volume valved holding chambers with beclomethasone/formoterol pressurized metered dose inhaler. J Aerosol Med Pulm Drug Deliv 2013; 26(4):223-227.

11. Mitchell JP, Coppolo DP, Nagel MW. Electrostatics and inhaled medications: influence on delivery via pressurized metered-dose inhalers and add-on devices. Respir Care 2007;52(3):283-300.

12. Saini D, Biris A, Srirama P, Mazumder M. Particle size and charge distribution analysis of pharmaceutical aerosols generated by inhalers. Pharm Dev Technol 2007;12(1):35-41.

13. Ali M, Mazumder MK, Martonen TB. Measurements of electrodynamic effects on the deposition of MDI and DPI aerosols in a replica cast of human oral-pharyngeal-laryngeal airways. J Aerosol Med Pulm Drug Deliv 2009;22(1):35-44.

14. Leung SSY, Chiow ACM, Ukkonen A, Chan H-K. Applicability of bipolar charge analyzer (BOLAR) in characterizing the bipolar electrostatic charge profile of commercial metered dose inhalers (MDIs). Pharm Res 2016;33(2):283-291.

15. Barry $\mathrm{P}, \mathrm{O}^{\prime} \mathrm{Callaghan} \mathrm{C}$. The effect of delay, multiple actuations and spacer static charge on the in vitro delivery of budesonide from the Nebuhaler. Br J Clin Pharmacol 1995;40(1):76-78.

16. Wildhaber J, Devadason S, Hayden M, James R, Dufty A, Fox R, et al. Electrostatic charge on a plastic spacer device influences the delivery of salbutamol. Eur Respir J 1996;9(9):1943-1946.

17. Pierart F, Wildhaber J, Vrancken I, Devadason S, Le Souef P. Washing plastic spacers in household detergent reduces electrostatic charge and greatly improves delivery. Eur Respir J 1999; 13(3):673-678

18. Global Initiative for Asthma. Global Strategy for Asthma Management and Prevention (2018). Available at: www.ginasthma.org. Accessed December 1, 2018

19. Barry PW, O'Callaghan C. The influence of inhaler selection on efficacy of asthma therapies. Adv Drug Deliv Rev 2003;55(7):879-923.

20. Saeed H, Mohsen M, Fink JB, Dailey P, Eldin AS, Abdelrahman $\mathrm{MM}$, et al. Fill volume, humidification and heat effects on aerosol delivery and fugitive emissions during noninvasive ventilation. J Drug Deliv Sci Technol 2017;39:372-378.

21. Hassan A, Rabea H, Hussein RRS, Salah Eldin R, Abdelrahman MM, Said ASA, et al. In-vitro characterization of the aerosolized dose during non-invasive automatic continuous positive airway pressure ventilation. Pulm Ther 2016;2(1):115-126.

22. Vincken W, Levy ML, Scullion J, Usmani OS, Dekhuijzen PR, Corrigan CJ. Spacer devices for inhaled therapy: why use them, and how? ERJ Open Res 2018;4(2). doi: 10.1183/23120541.00065-2018.

23. Anderson G, Johnson N, Mulgirigama A, Aggarwal B. Use of spacers for patients treated with pressurized metered dose inhalers: focus on the VENTOLINTM Mini Spacer. Expert Opin Drug Deliv 2018; 15(4):419-430. 


\section{Disposable vs Traditional Spacers For PMDI}

24. Silkstone V, Corlett S, Chrystyn H. Relative lung and total systemic bioavailability following inhalation from a metered dose inhaler compared with a metered dose inhaler attached to a large volume plastic spacer and a jet nebuliser. Eur J Clin Pharmacol 2002;57(11):781-786.

25. Hindle M, Chrystyn H. Relative bioavailability of salbutamol to the lung following inhalation using metered dose inhalation methods and spacer devices. Thorax 1994;49(6):549-553.
26. Selroos O, Halme M. Effect of a volumatic spacer and mouth rinsing on systemic absorption of inhaled corticosteroids from a metered dose inhaler and dry powder inhaler. Thorax 1991;46(12):891-894.

27. Sanders M, Tran C. Can a single-use spacer be used effectively on multiple occasions? Abstract 34. The Primary Care Respiratory Society. Available at: https://www.pcrs-uk.org/pcru\#collapse-1-3. Accessed July 12, 2019. 